\title{
'n Voorlopige model vir die sistematiese beskrywing van gebruikersvriendelikheid in woordeboeke
}

Herman L. Beyer, Departement Germaanse en Romaanse Tale, Universiteit van Namibië, Windhoek, Namibië en Departement Afrikaans en Nederlands,

Universiteit van Stellenbosch, Stellenbosch, Republiek van Suid-Afrika

(hbeyer@unam.na)

Opsomming: Die gebruikersperspektief staan tans sentraal in die leksikografiese gesprek. Dit spruit uit die beginsel dat enige woordeboek in die eerste plek vir gebruik deur ' $n$ bepaalde teikengebruikersgroep bedoel moet wees, en as sodanig moet die woordeboek op daardie gebruikersgroep afgestem wees - dit moet gebruikersvriendelik wees. In hierdie artikel word van die standpunt uitgegaan dat die gebruik van 'n woordeboek as 'n kommunikatiewe handeling begryp moet word, wat die geleentheid bied om insigte uit die kommunikasiewetenskap in die metaleksikografie te benut. Na aanleiding van die algemene kommunikasiemodel vir interpersoonlike kommunikasie wat in die literatuur oor kommunikasiewetenskap voorkom, word 'n leksikografiese kommunikasiemodel voorgestel. Uit hierdie model kan minstens elf leksikografiese parameters afgelei word aan die hand waarvan gebruikersvriendelikheid in woordeboeke sistematies beskryf kan word. Die struktuur wat hierdie parameters aan 'n gesprek oor gebruikersvriendelikheid in woordeboeke kan gee, bemiddel die formulering van die ware doel van 'n gebruikersvriendelike woordeboek.

Sleutelwoorde: GEBRUIK, GEBRUIKER, GEBRUIKERSPERSPEKTIEF, GEBRUIKERSVERWYSINGSRAAMWERK, GEBRUIKERSVRIENDELIKHEID, KANAAL, KOMMUNIKASIEMODEL, KONTEKS, LEKSIKOGRAAF, LEKSIKOGRAFIESE KOMMUNIKASIEMODEL, MEDIUM, METATEKS, STYLGIDS, TERUGVOER, WERKLIKE DOEL, WOORDEBOEK, WOORDEBOEKPLAN

\footnotetext{
Abstract: A Preliminary Model for the Systematic Description of Userfriendliness in Dictionaries. The user perspective is a central notion in current lexicographical discourse. This stems from the principle that a dictionary should in the first place be

Hierdie artikel is 'n verwerking van 'n gedeelte van 'n hoofstuk uit 'n D.Litt.-proefskrif, ' $n$ Metaleksikografiese ondersoek na konteksleiding in Afrikaanse vertalende woordeboeke, wat in April 2006 deur die Universiteit van Stellenbosch, Stellenbosch, Republiek van Suid-Afrika, aanvaar is. ' $n$ Verkorte Engelse weergawe is as referaat gelewer by die Elfde Internasionale Konferensie van die African Association for Lexicography, georganiseer deur die Tshivenda Nasionale Leksikografie-eenheid, Universiteit van Venda vir Wetenskap en Tegnologie, Thohoyandou, Republiek van Suid-Afrika, 5-7 Julie 2006.
} 
meant for use by a specific target user group, and as such the dictionary should be aimed at that target user group - it should be user friendly. In this article the point of departure is that the use of a dictionary should be regarded as a communicative act, which presents the opportunity to utilise insights gained in communication science in the metalexicography. From the general communication model for interpersonal communication, as found in literature on communication science, a lexicographical communication model is developed. From this model at least eleven lexicographical parameters can be derived according to which user-friendliness in dictionaries can be described in a systematic way. The structure that these parameters can offer in debating user-friendliness in dictionaries informs the formulation of a definition for the genuine purpose of a user-friendly dictionary.

Keywords: CHANNEL, COMMUNICATION MODEL, CONTEXT, DICTIONARY PLAN, DICTIONARY, FEEDBACK, GENUINE PURPOSE, LEXICOGRAPHER, LEXICOGRAPHICAL COMMUNICATION MODEL, MEDIUM, METATEXT, STYLE GUIDE, USE, USER, USER'S FRAME OF REFERENCE, USER'S PERSPECTIVE, USER-FRIENDLINESS

\section{Inleiding}

Die gebruikersperspektief staan tans sentraal in die leksikografiese gesprek. Dit spruit uit die beginsel dat enige woordeboek in die eerste plek vir gebruik deur ' $n$ bepaalde teikengebruikersgroep bedoel is, en as sodanig moet die woordeboek op daardie gebruikersgroep afgestem wees - dit moet gebruikersvriendelik wees (vgl. Gouws en Prinsloo 2005: 39).

Volgens Kühn (1989: 112) moet die gebruik van 'n woordeboek as 'n kommunikatiewe handeling begryp word. Wiegand (1996: 135) betoog dat die woordeboek 'n draer van tekssoorte is, en dit veronderstel 'n kommunikasiesituasie, want tekste kan as kommunikasie beskou word (vgl. Van Cuilenburg et al. 1992: 21), of, meer presies, as media vir kommunikasie (vgl. Steinberg 1994: 15; en Smit 1996: 171). Hierdie siening bied die geleentheid om insigte uit die kommunikasiewetenskap in die metaleksikografie te benut om 'n raamwerk vir die sistematiese beskrywing van gebruikersvriendelikheid in woordeboeke te ontwerp. Dit is wat met hierdie artikel beoog word.

\section{2. 'n Interpersoonlike kommunikasiemodel}

Variante van die algemene kommunikasiemodel vir interpersoonlike kommunikasie word byna sonder uitsondering in die literatuur oor kommunikasiewetenskap voorgehou (vgl. o.m. Van Cuilenburg et al. 1992: 9-11; Frost et al. 1993: 5-49; Janssen 1996: 23-30; Steehouder et al. 1999: 22-25; en Guffey 2001: 45). Die vertaalde voorstelling van Van der Molen et al. (1995: 13-19) sal vir die doel van hierdie bespreking gebruik word. Hoewel die model op interpersoonlike kommunikasie gerig is, word die nut daarvan vir die metaleksikografie nie uitgesluit nie; die naslaanproses kan immers as 'n soort "gesprek" tussen leksi- 
kograaf en woordeboekgebruiker beskou word, hoewel oënskynlik slegs eenrigtingkommunikasie ter sprake is (vgl. Gouws 1989: 14). Vergelyk die skematiese voorstelling van die model in figuur 1.

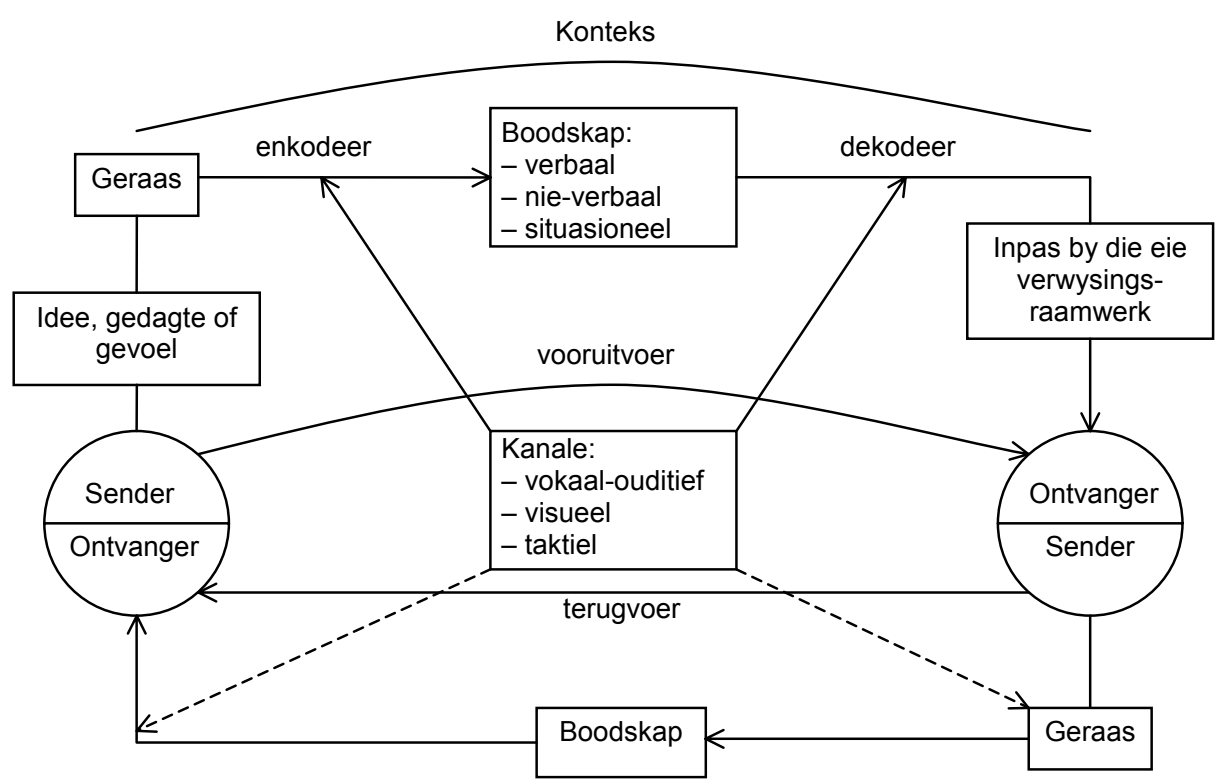

Figuur 1: Die volledige kommunikasiemodel van Van der Molen et al. (1995)

Die skema hierbo kan soos volg toegelig word:

Die sender het 'n bepaalde idee, gedagte of gevoel wat hy/sy aan die ontvanger wil oordra. Hierdie idee, gedagte of gevoel benodig ' $n$ verpakking of voertuig, en meestal word van taal gebruik gemaak. Die sender skakel dus die idee, gedagte of gevoel (in taal) om - hy/sy enkodeer die inligting en die boodskap (in verbale, nie-verbale of situasionele vorm) kom tot stand. Ten einde die boodskap te verstaan, moet die ontvanger dit dekodeer. 'n Voorvereiste vir suksesvolle dekodering is dat beide die ontvanger en die sender die kode wat laasgenoemde gebruik, moet beheers. Die interpretasie van die gedekodeerde boodskap vind plaas binne die verwysingsraamwerk van die ontvanger - dit is die geheel van norme, waardes, opvattinge en vanselfsprekendhede op grond waarvan die ontvanger handel en sy/haar omgewing beoordeel. Die kommunikasieproses vind deur die vokaal-ouditiewe, die visuele en die taktiele kanale plaas. Geraas is alles wat die ontvangs en suksesvolle interpretasie van die boodskap versteur. Drie soorte geraas kan onderskei word: fisiese geraas (bv. as iemand met 'n lugdrukboor buite die oop venster werk wanneer twee persone in die kamer ' $n$ gesprek probeer voer), psigologiese geraas (vooroordele en stereotiepe opvattinge wat die deurgang van die sein belemmer) en semantiese geraas (wanneer die twee partye betrokke by die kommunikasie nie 
dieselfde kode beheers nie, maar ook byvoorbeeld die gebruik van jargon teenoor 'n leek). 'n Boodskap het 'n vooruitvoer-funksie indien dit iets aankondig oor die boodskap wat gaan volg, bv. "Ek hoop jy sal my nou nie kwalik neem nie, maar ..." Terugvoer behels die ontvanger se reaksie op die boodskap, en gee die sender gewoonlik die geleentheid om vas te stel of sy/haar boodskap korrek geïnterpreteer is. Dan keer die rolle om, en die oorspronklike ontvanger word nou die sender, terwyl die oorspronklike sender nou die ontvanger is. Die konteks verwys na die omgewing waarbinne die kommunikasie plaasvind, hetsy fisies, hetsy psigologies-sosiaal.

\section{3. 'n Leksikografiese kommunikasiemodel}

Die algemene model vir interpersoonlike kommunikasie kan aangepas word om die kommunikatiewe handeling van woordeboekgebruik sistematies voor te stel. Die produk van dié aanpassing is 'n leksikografiese kommunikasiemodel, wat in figuur 2 aangebied word:

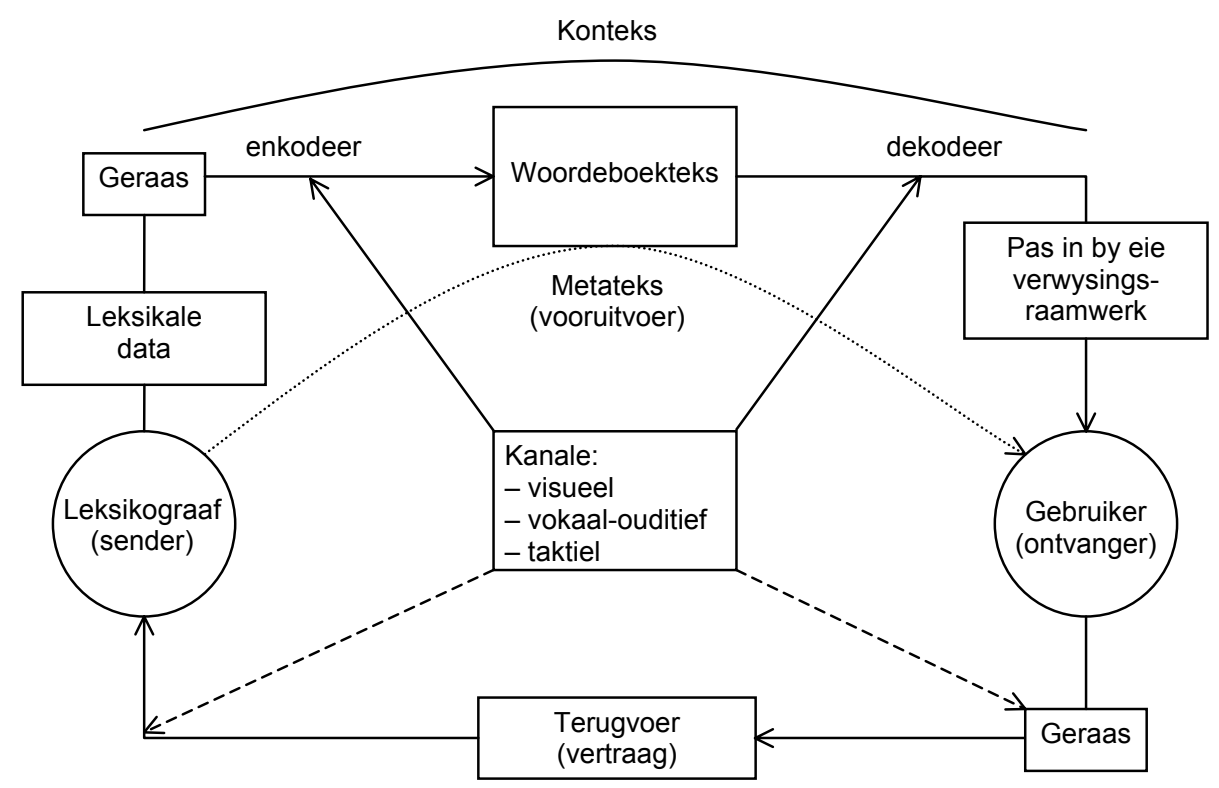

Figuur 2: 'n Leksikografiese kommunikasiemodel

Die skema in figuur 2 kan soos volg toegelig word:

Die leksikograaf het die taak om leksikale data tot 'n woordeboekteks te verwerk wat vir die teikengebruiker nuttig sal wees. Geraas kan die leksikograaf verhinder om 'n optimaal benutbare woordeboekteks saam te stel: gewoon onkundigheid; gebrek aan kennis oor die behoeftes van die woordeboek- 
gebruikers, hulle naslaanvaardighede en die doel waarvoor die woordeboek gebruik word; ens. Die leksikograaf enkodeer die leksikale data volgens die stylgids tot ' $n$ woordeboekteks met ' $n$ bepaalde struktuur. Die woordeboekteks word deur ' $n$ bepaalde medium aangebied, waarvan die gebruiklikste die gedrukte en elektroniese media is. Die woordeboekgebruiker lees die woordeboekteks en dekodeer dit deur die teksstruktuur te agterhaal en die relevante datakategorieë in hulle soeksones te identifiseer en die gesoekte inligting te ekstraheer aan die hand van leiding wat in die metateks aangebied word. Die metateks (gebruikersgids) geld as vooruitvoer: Die gebruiker wat die metateks raadpleeg, weet wat die aard van die woordeboek is en watter datakategorieë hy/sy in woordeboekartikels kan vind, ook hoe dit aangebied word. Hierdie vooruitvoer geld egter in weinig gevalle, aangesien min gebruikers die metateks van ' $n$ woordeboek raadpleeg. In te veel gevalle bestaan 'n bruikbare metateks ook glad nie; derhalwe word die verband in figuur 2 deur 'n stippellyn aangedui. Funksionele vooruitvoer kan geraas minimaliseer. Geraas kan die woordeboekgebruiker verhinder om die woordeboekteks optimaal te dekodeer as gevolg van gebrekkige kennis van woordeboektipes wat aanleiding gee tot die gebruik van die verkeerde woordeboeke, gebrekkige kennis van die teksstruktuur, die nie-raadpleging van die metateks, ens. Die woordeboekgebruiker pas die interpretasie van die data in die woordeboekteks by sy/haar verwysingsraamwerk in deur byvoorbeeld te glo dat indien 'n leksikale item nie in 'n woordeboek gelemmatiseer is nie (d.w.s. indien die betrokke woordeboekartikel afwesig is), daardie leksikale item nie bestaan nie (verwysingsraamwerk: 'n woordeboek bevat al die leksikale items van die behandelde taal se leksikon). Wanneer woordeboekgebruikers terugvoer gee, is hulle dalk nie in staat om dit optimaal te doen nie, aangesien hulle nie met die terminologie en werkswyses van die leksikografie vertroud is nie. Terugvoer word gewoonlik in die vorm van resensies in die pers en korrespondensie tussen gebruikers en die uitgewer en/of die leksikograaf gegee. Sodanige terugvoer is gewoonlik beperk en vertraag (anders as in die geval van die interpersoonlike gespreksituasie). Leksikograwe kan ook persoonlike telefoonoproepe en besoeke ontvang, in welke geval die vokaal-ouditiewe kanaal gebruik word. Geraas kan veroorsaak dat leksikograwe kritiek kan waninterpreteer of as onbelangrik kan beskou, of dit gewoon nie verstaan nie. Die konteks waarbinne die kommunikasie tussen leksikograaf en woordeboekgebruiker afspeel, is die omgewing waarbinne sowel die saamstel as die gebruik van die woordeboekteks plaasvind, bv. in ' $n$ multitalige, demokratiese Suid-Afrika. Dit kan ook verwys na die onmiddellike gebruiksituasie waarin die gebruiker hom/haar bevind, bv. in 'n onderrigsituasie in 'n klaskamer. Woordeboektekste word by uitstek deur die visuele kanaal aangebied, aangesien gebruikers die artikels visueel waarneem wanneer hulle dit lees. ' $n$ Uitsondering is braille-woordeboeke, waar die taktiele kanaal gebruik word. Die vokaal-ouditiewe kanaal kan ook by die gebruik van elektroniese woordeboeke benut word.

Die leksikografiese kommunikasiemodel akkommodeer die woordeboekplan soos deur Prinsloo en Gouws (2005: 13-19) beskryf. Binne die model 
enkapsuleer die woordeboekplan die leksikograaf as sender, die leksikale data wat verwerk moet word, die enkoderingsproses en die ontwerp en saamstel van die metateks te midde van geraas, om 'n woordeboekteks tot stand te bring. Sowel die organisasieplan as die woordeboekkonseptualiseringsplan as komponente van die woordeboekplan kom binne die model tot hul reg. In figuur 3 hieronder word die terrein van die woordeboekplan in die leksikografiese kommunikasiemodel deur die donker geskakeerde area aangedui:

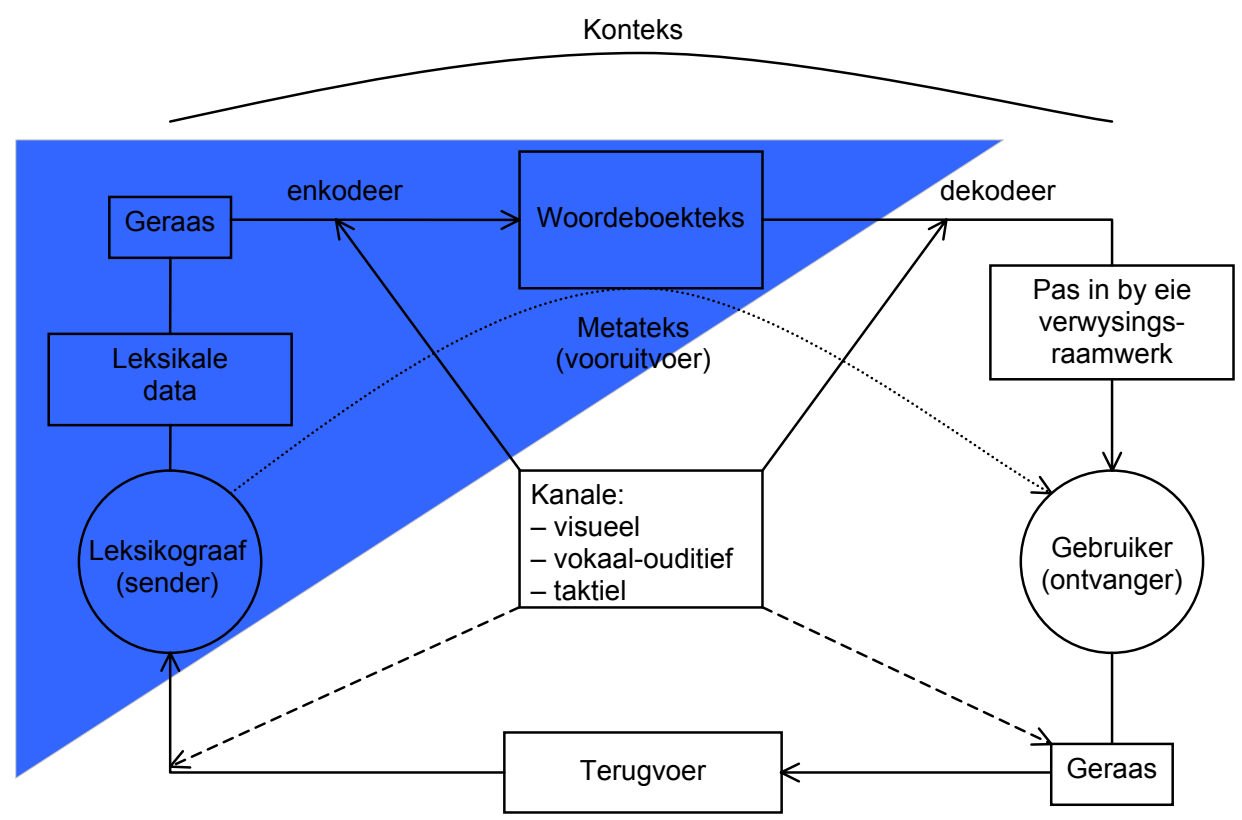

Figuur 3: Die terrein van die woordeboekplan in die leksikografiese kommunikasiemodel

Hoewel kommunikasiemodelkomponente soos die gebruiker nie direk binne die sfeer van die woordeboekplan as deel van die leksikografiese proses val nie, beteken dit nie dat die waardes van hierdie komponente in die uitvoering van die woordeboekplan genegeer word nie; inteendeel, die leksikografiese kommunikasiemodel moet juis ten doel hê om die leksikografiese beplanner in sy/haar taak te rig deurdat spesifieke waardes aan komponente soos "dekodeer", "gebruiker", "geraas" en "terugvoer" in die beplanningsproses toegeken kan word. Die waardes wat so aan hierdie komponente toegeken word, bepaal juis die waardes wat tydens die beplanningsproses toegeken sal word aan die komponente wat wel deel uitmaak van die woordeboekplan. Hierdie tipe holistiese leksikografies-kommunikatiewe benadering lei daartoe dat spesifieke beduidende leksikografiese parameters geïdentifiseer kan word wat op hulle 
beurt die komponente van 'n leksikografiese model vir gebruikersvriendelike woordeboeke kan vorm.

\section{4. 'n Leksikografiese model vir gebruikersvriendelike woordeboeke}

Van der Molen et al. (1995: 19) erken dat hulle algemene kommunikasiemodel "een vereenvoudigde weergave van de werkelijkheid en bovendien een erg algemene en statische weergave" is, en dieselfde geld waarskynlik in 'n mindere of meerdere mate die leksikografiese kommunikasiemodel wat daarvan afgelei is, maar dié model skep 'n funksionele raamwerk waarbinne die leksikografiese gebruikersperspektief op 'n wetenskaplike basis gedefinieer en aangepak kan word. Na aanleiding daarvan kan die volgende parameters geïdentifiseer word wat bepalend is in 'n gebruikersgedrewe leksikografie:

1. Die woordeboekparameter

2. Die leksikograafparameter

3. Die stylgidsparameter

4. Die gebruikersparameter

5. Die gebruiksparameter

6. Die gebruikersverwysingsraamwerkparameter

7. Die mediumparameter

8. Die kanaalparameter

9. Die metateksparameter

10. Die konteksparameter

11. Die terugvoerparameter

Elkeen van hierdie parameters word vervolgens kortliks beskryf.

\subsection{Die woordeboekparameter}

Die woordeboekparameter kan as die sentrale parameter beskou word. $\mathrm{Al}$ die ander parameters bepaal direk en in kombinasie met mekaar die waardes van die veranderlikes binne hierdie parameter. Die verhouding is egter nie eensydig nie: Die woordeboekparameter kan ook die waardes van die veranderlikes binne elk van die ander parameters bepaal, soos wat uit die volgende bespreking sal blyk.

Die woordeboekparameter sluit daardie veranderlikes in wat te doen het met die tipologiese plasing, werklike doel en funksies van die woordeboek, die dataverspreidingsprogram en die mikrostrukturele program (vgl. Gouws 2001: 
68). Die invloed van die ander parameters bepaal hoe effektief, hoe gebruikersvriendelik die waardes van hierdie veranderlikes in die woordeboekeindproduk neerslag sal vind, terwyl die waardes van die veranderlikes binne hierdie parameter die raamwerk skep wat bepaal watter veranderlikes binne die ander parameters geld.

\subsection{Die leksikograafparameter}

Die leksikograafparameter is waarskynlik dié belangrikste parameter; dit blyk uit die feit dat die metaleksikografiese literatuur oor die gebruikersaspek oorwegend op hierdie parameter fokus, en dat die leksikograaf die rolspeler is wat uiteindelik vir die saamstel van die woordeboekteks verantwoordelik is. Kromann et al. (1991: 2713) som hierdie parameter goed op deur te sê dat dit gaan oor "consideration on the part of the lexicographer for the dictionary's target group, its needs and the types of user situations" [my kursivering - HLB].

Die leksikograafparameter kan dus beskryf word in terme van alles wat die leksikograaf kan en moet doen om die teikengebruiker ter wille te wees in die saamstel van die woordeboekteks, maar ook alles wat die leksikograaf nié (kan) doen nie as gevolg van 'n gebrek aan kennis oor die teikengebruiker. Hierby moet gevoeg word alles wat die metaleksikograaf van die leksikograaf weet, en behoort te weet, bv. hoe hy/sy te werk gaan in die ontwerp van 'n woordeboek(teks), ten einde hom/haar van hulp te kan wees (vgl. Swanepoel 2001: 170). Die mees fundamentele vereiste hier is dat die leksikograaf opgelei moet wees (vgl. in hierdie verband o.a. Martin 1994; Botha en Botha 1998; en Gouws 2001: 60-65). Trouens, Bergenholtz en Gouws (2006: 31) is van mening dat die leksikografiese proses by die opleiding van leksikograwe kan begin, selfs voordat te veel aandag aan die finansiële implikasies van die beplande woordeboekprojek bestee word. Verder maak die leksikograaf staat op die resultate van navorsing oor die gebruiker, sy/haar behoeftes, naslaanvaardighede, taalvaardighede in die behandelde taal of tale, ens. 'n Gebrek aan kennis oor en insig in hierdie faktore veroorsaak dat die leksikograaf woordeboeke en woordeboektekste ontwerp wat nie aan die behoeftes van die teikengebruiker voldoen nie. Ongelukkig bestaan daar juis weinig studies oor die woordeboekgebruiker en sy/haar behoeftes en vaardighede; derhalwe behoort die aanpak van sulke studies as prioriteit beskou te word indien die doel is om die leksikograafparameter 'n positiewe invloed op gebruikersgedrewe leksikografie te laat uitoefen (vgl. 4.4). Navorsing van dié aard behoort ook op wetenskaplik-empiriese basis gedoen te word, wat eksperimentele studies insluit; indien dit nie die geval is nie, "much of these research results can only be used as basis for preliminary hypotheses about the design of a functional dictionary of a specific kind" (Swanepoel 2001: 173).

$\mathrm{Na}$ aanleiding van die voorafgaande bespreking sou die belangrikste veranderlikes wat binne die leksikograafparameter geld, kwessies insluit soos die leksikograaf se opleiding, sy/haar konsep van die teikengebruiker, sy/haar 
kennis van die leksikografieteorie, kennis van die behandelde taal of tale (en die relevante leksikale domein in die geval van 'n vakwoordeboek) en kennis van die taalwetenskap.

\subsection{Die stylgidsparameter}

Die stylgidsparameter kan van die leksikograafparameter onderskei word, aangesien dit nie altyd die leksikograaf is wat die stylgids opstel nie. Veral in die geval van omvattende woordeboeke, waarvan die produksie oor dekades strek, word nuwe leksikograwe wat by sodanige projekte aansluit, bekend gemaak met die toepassing van die stylgids - hulle was self nie by die opstel daarvan betrokke nie. Hierdie stand van sake stel minstens twee vereistes aan (die opsteller van) die stylgids: (a) die stylgids moet die dataverspreidingsprogram van die woordeboek duidelik uiteensit, en (b) dit moet vir die leksikograaf verstaanbaar en toepasbaar (d.w.s. gebruikersvriendelik) wees. Hierby kan die kritiese vereiste gevoeg word dat die stylgids in die metateks verantwoord moet kan word. Die stylgidsparameter is by uitstek dié parameter wat die konsekwente aanbod van leksikografiese data in die woordeboek moet reguleer en sodoende die woordeboek gebruikersvriendelik maak (vgl. Gouws 2001: 67).

\subsection{Die gebruikersparameter}

Teenoor die leksikograaf as sender staan die gebruiker as ontvanger in die woordeboekkommunikasiesituasie.

Literatuur wat handel oor die behoefte aan en vereiste van navorsing oor die teikengebruiker en die vereiste dat 'n woordeboek op die teikengebruiker afgestem moet wees, sowel as die feit dat onvoldoende navorsing tot op hede hieroor gedoen is, sluit in Wiegand (o.a. 1984; 1985), Gouws (1989: 49; 1990: 55; 1996; 1996a; 1999; 2001: 66, 72), Hartmann (1989), Kromann et al. (1991), Alberts (1992), Svensén (1993: 4, 16, 17), Lombard (1994), Louw (1997: 2 e.v.), FouchéVan der Merwe (1999), Prinsloo en Gouws (2000), en Swanepoel (2001). Uit hierdie literatuur kan afgelei word dat die leksikograaf inligting oor minstens die volgende aspekte van die teikengebruiker moet inwin en integreer in die beplanning van sy/haar woordeboek:

(a) die teikengebruiker se taalkennis, beide van die bron- en die doeltaal van die woordeboek,

(b) die gebruiker se naslaanvaardighede, en

(c) die taal- en inligtingsbehoeftes van die gebruiker.

Dat dié inligting die leksikograaf tans nog ontbreek, word duidelik uit waarnemings soos die volgende: 
(a) Gebruikers beskik nie oor genoegsame linguistiese en pragmatiese insig om die inligting in die woordeboek suksesvol te ontsluit nie (vgl. Gouws 1996: 21).

(b) Gebruikers toon 'n weersin in woordeboekgebruik (vgl. Carstens 1995: 107).

(c) Gebruikers ken nie die woordeboektipes wat bestaan nie (vgl. Carstens 1995: 108).

(d) Gebruikers beskik oor onvoldoende naslaanvaardighede (vgl. Carstens 1995: 113).

(e) Gebruikers beskik nie oor voldoende ondervinding in die gebruik van woordeboeke nie.

Die onderskeid tussen die leksikograafparameter en gebruikersparameter ondersteun die insig dat 'n gebruikersvriendelike woordeboek die produk van én die leksikograaf én die kundige teikengebruiker is. Die vestiging van 'n woordeboekkultuur sal van die teikengebruiker 'n kundige teikengebruiker maak (vgl. Gouws en Prinsloo 2005: 42).

\subsection{Die gebruiksparameter}

Die gebruiksparameter verwys na die onmiddellike situasie wat woordeboekgebruik stimuleer, bv. in die vreemdetaalklaskamer of in 'n vertaalsituasie om 'n gepaste moedertaalekwivalent vir ' $n$ vreemdetaalitem te vind ten einde ' $n$ vreemdetaalteks te verstaan (en te vertaal). Tydens die beplanning van 'n woordeboek moet die tipiese gebruiksituasies waarin die beplande woordeboek gebruik sal word, so ver moontlik voorsien (en tydens die bemarking van die woordeboek aangedui) word, sodat die strukture in die woordeboek op daardie situasies afgestem kan word.

Uit die literatuur wil dit soms lyk asof die gebruiksituasie as deel van die gebruikerskenmerke beskou word. Hier is dit egter belangrik om dié twee parameters van mekaar te onderskei, aangesien die veranderlikes wat die gebruiksparameter bepaal, nie noodwendig ' $n$ invloed op die veranderlikes wat die gebruikersparameter bepaal, uitoefen nie. 'n Geografiewoordeboek kan vir die spesifieke gebruiksituasie van die geografieklas bedoel wees, hoewel die gebruikersparameter se veranderlikes grootliks identies kan wees aan dié wat vir die standaard verklarende woordeboek vir spesifieke gebruik in die taalklas geïdentifiseer is. Hoewel die gebruikersparameters vir die twee woordeboeke grootliks identies is, verskil die gebruiksparameters beduidend. Die feit dat die twee parameters van mekaar onderskei word, beteken egter nie dat hulle sonder mekaar kan funksioneer nie; soos die ander parameters, figureer dié twee parameters as onmisbare elemente in die bepaling van die werklike doel van 'n woordeboek. 
Vanuit 'n kognitief-funksionele benadering identifiseer Swanepoel (2001: 176) agt vrae in terme waarvan woordeboekgebruiksituasies beskryf kan word:

(a) Vir watter presiese take (lees, skryf, vertaling, woordeskatverwerwing, ens.) word verskillende soorte woordeboeke gebruik?

(b) Watter kognitiewe prosesse, vaardighede, strategieë en mentale voorstelling is betrokke by die suksesvolle uitvoering van so 'n taak?

(c) Watter rol speel leksikale kennis in die uitvoering van die taak?

(d) Wat is leksikale kennis?

(e) Hoe word leksikale kennis in die mentale leksikon geberg en hoe word daartoe kennis verkry?

(f) Watter soorte gapings kan in die gebruiker se leksikale kennis ontstaan en watter implikasies het dit vir die suksesvolle uitvoering van die taak?

(g) Watter strategieë, behalwe om 'n woordeboek te raadpleeg, kan die gebruiker inspan om vir hierdie leksikale leemte te kompenseer?

(h) Onder watter omstandighede sal gebruikers hulle tot 'n woordeboek wend om 'n gaping in hulle leksikale kennis te hanteer?

Navorsing oor hierdie belangrike aspek ontbreek in die metaleksikografie (vgl. Swanepoel 2001: 186).

\subsection{Die gebruikersverwysingsraamwerkparameter}

Hierdie parameter onderskei hom van die gebruikersparameter daarin dat die gebruikersparameter hoofsaaklik verwys na vaardighede en kennis wat redelikerwys van die woordeboekgebruiker verwag kan word om voordeel uit 'n gebruikersvriendelike woordeboek te trek, d.w.s. om 'n kundige gebruiker te wees. Die gebruikersverwysingsraamwerkparameter het 'n breër bestek. Dit gaan hier naamlik oor veronderstellings, gewoontes, persepsies en houdings. Bepaalde veronderstellings is byvoorbeeld agterhaalbaar uit die volgende aanhalings van taalgebruikers:

"As daardie woord nie in die woordeboek staan nie, bestaan dit nie."

"As daardie woord in die woordeboek staan, kan ek dit gebruik waar en wanneer ek wil."

Gouws (1989: 13) wys op die algemene persepsie dat 'n woordeboek dié bron van gesag oor taalsake is:

Vir die gewone taalgebruiker is 'n woordeboek die belangrikste boek wat oor taal geskryf is. Hierdie onbevange gebruiker dink aan sy taalkundige hulpbron 
as die woordeboek en nie as 'n woordeboek nie. 'n Publikasie met woordeboek in sy titel verkondig die absolute waarheid.

Deur verantwoordelike en gebruikersvriendelike leksikografiebeoefening kan die leksikograaf ook sekere wanpersepsies teenwerk, soos dié wat deur die aanhalings hierbo verteenwoordig word.

Die gebruikersverwysingsraamwerkparameter word egter ook deur ander veranderlikes bepaal. Woordeboekgebruikers het naamlik bepaalde gewoontes en verwagtinge van woordeboeke, bv. dat die lemmata daarin alfabeties gerangskik is. Read (1973: 178) maak die invloed van hierdie veranderlike duidelik:

There is a constant pulling and hauling between what a lexicographer would like to do on scientific grounds, and what he is compelled to do by the habitual demands of the public.

Vir 'n woordeboek om optimaal gebruikersvriendelik te wees, moet dit binne die (woordeboek)verwysingsraamwerk van die teikengebruiker figureer. Gouws (1999: 7) verwys hierna as die aanpassing van die leksikografie by die maatskappy. Indien die leksikograaf daarin slaag om aspekte van die verwysingsraamwerk van die gebruikers ten gunste van gebruikersvriendelike woordeboeke aan te pas, sal daar sprake wees van die aanpassing van die maatskappy by die leksikografie (vgl. nogmaals Gouws 1999: 7). Dit sal byvoorbeeld gebeur indien onderwysers en onderwyskundiges oortuig kan word van die waarde wat 'n komponent oor woordeboekgebruik in enige taalleerplan het (vgl. Gouws 1996: 182). Die gebruikersverwysingsraamwerkparameter kan dus inspeel op die gebruikersparameter. Die omgekeerde is ook waar: Indien woordeboekgebruikers byvoorbeeld konstant in hulle naslaanpogings deur gebruikersonvriendelike woordeboeke gefrustreer word, kan hulle 'n weersin in woordeboeke en woordeboekgebruik ontwikkel — 'n verskynsel wat volgens Carstens (1995: 107) ongelukkig reeds voorkom.

Die mate van aanpassing van die leksikografie by die maatskappy word deur die leksikograafparameter bepaal, bv. die saamstel van 'n nuwe tipe woordeboek nadat die behoefte daartoe deur empiriese navorsing vasgestel en onder die leksikograaf se aandag gebring is. Die mate van aanpassing van die maatskappy by die leksikografie word deur die gebruikersverwysingsraamwerkparameter bepaal.

\subsection{Die mediumparameter}

Woordeboeke word vandag hoofsaaklik deur twee media versprei, naamlik die gedrukte medium en die elektroniese medium. 'n Gebruikersvriendelike woordeboek sal in die gepaste medium beskikbaar wees: Die reisende joernalis kan 'n elektroniese woordeboek wat op sy/haar skootrekenaar geïnstalleer is meer gebruikersvriendelik vind as 'n papierwoordeboek; daarenteen kan skole woor- 
deboeke in die gedrukte medium verkies, aangesien rekenaarfasiliteite relatief beperk is en dus toegang tot 'n elektroniese woordeboek moeilik (gebruikersonvriendelik) maak.

Veranderlikes wat die waarde van die mediumparameter bepaal, is byvoorbeeld papierkwaliteit en bindkwaliteit in die geval van gedrukte woordeboeke, en die programmatuur wat gebruik is in die saamstel van die woordeboek en waarmee die woordeboek versoenbaar is in die geval van elektroniese woordeboeke. In die geval van internetwoordeboeke is die beskikbaarheid van internettoegang vir die teikengebruiker 'n kernveranderlike.

Die gekose medium stel egter ook vereistes aan die leksikograaf. Indien die gedrukte medium gekies word, word die leksikograaf 'n beperking op ruimte opgelê, aangesien 'n gedrukte woordeboek wat gebruikersvriendelik wil wees, ook fisies hanteerbaar en bekostigbaar moet wees. Die beperking op ruimte lei die leksikograaf om bepaalde strategieë aan te wend om ruimte te bespaar, waarvan die algemeenste prosedure dié van teksverdigting is. Teksverdigting word nie primêr deur die strewe na gebruikersvriendelikheid gemotiveer nie, maar deur die beperkte ruimte wat deur die gekose medium opgelê word. Teksverdigting as sodanig werk teoreties juis gebruikersvriendelikheid teen. Die ruimtebesparende strategie van teksverdigting het 'n diep gewortelde leksikografiese tradisie geword en kom selfs voor in media wat nie die mate van ruimtebeperking op die leksikograaf plaas wat deur die gedrukte medium op hom/haar geplaas word nie. Dit word duidelik as elektroniese woordeboeke beskou word: In die meeste gevalle word tradisionele teksverdigtingstrategieë toegepas, hoewel die medium dit nie dikteer nie. In sommige gevalle is elektroniese woordeboeke (soos die Elektroniese Verklarende Handwoordeboek van die Afrikaanse Taal 2.00 (2000) en Pharos Woordeboeke/Dictionaries: 5 in 1 (2000)) bloot rekenaarmatige aanpassings van reeds bestaande gedrukte woordeboeke (Louw 2001: 324).

Hoewel 'n sekere mate van teksverdigting sal voorkom selfs waar die medium nie ernstige beperkinge op ruimte plaas nie, juis omdat die totale afwesigheid van teksverdigting ook gebruikersonvriendelik sal wees omdat dit die naslaanproses sal kompliseer, behoort die samestellers van elektroniese woordeboeke nie teksverdigtingstrategieë wat in die gedrukte medium voorkom, slaafs te dupliseer nie, maar behoort hulle die virtueel onbeperkte ruimte tot hulle beskikking in dié verband innoverend te benut. Teksverdigtingstrategieë in gedrukte woordeboeke wat ten doel het om gebruikersvriendelikheid in die hand werk, sal nie noodwendig dieselfde effek in elektroniese woordeboeke hê nie. Dit blyk dus dat navorsing oor elektroniesewoordeboekgebruik noodsaaklik is. Louw (2000: 292) wys ook op die dringende behoefte aan 'n metaleksikografiese gesprek oor elektroniese woordeboeke in die algemeen. In hierdie verband is dit verblydend dat daar tans by SIGNA, dit is die Stellenbosse Instituut vir Gevorderde Navorsing, deur Suid-Afrikaanse en buitelandse navorsers gewerk word aan 'n uitvoerige navorsingsprojek om 'n teoretiese model vir elektroniese woordeboeke te ontwikkel. 


\subsection{Die kanaalparameter}

Tradisioneel is die waarde van die kanaalparameter die visuele kanaal (woordeboekgebruikers neem die woordeboekartikels visueel waar wanneer hulle dit lees). Die uitsondering op hierdie reël is braille-woordeboeke, waar die waarde van die kanaalparameter die taktiele kanaal is. Uiteraard sal ' $n$ woordeboek wat blinde gebruikers teiken, hoogs gebruikersonvriendelik wees indien dit deur die visuele kanaal aangebied word. Met die ontwikkeling van spesifiek die rekenaartegnologie is dit ook moontlik om die vokaal-ouditiewe kanaal naas die visuele kanaal in 'n elektroniese woordeboek te gebruik: Deur byvoorbeeld op die fonetiese transkripsie van ' $n$ lemma of op 'n spesiale ikoon op die rekenaarskerm te klik, kan 'n klanklêer geaktiveer word en die gebruiker kan die uitspraak van die lemma of 'n ander mikrostrukturele inskrywing ouditief waarneem. Vergelyk in hierdie verband byvoorbeeld die Oxford Talking Dictionary (1998).

\subsection{Die metateksparameter}

Die metateks (gebruikersgids) verduidelik die werkswyse van die woordeboek aan die gebruiker. Indien die waarde van die metateksparameter "afwesig" is, word die gebruikersvriendelikheid van die woordeboek sterk negatief beïnvloed. Die omgekeerde is nie noodwendig waar indien die metateksparameter se waarde "aanwesig" is nie, aangesien die kwaliteit van die metateks so minderwaardig kan wees dat dit vir die woordeboekgebruiker geen waarde inhou nie. Die metateksparameter moet dus as 'n skalêre veranderlike geld. Vergelyk Kirkpatrick (1989) vir 'n bespreking van metatekste in woordeboeke.

Die metateks is in wese ' $n$ instruktiewe teks, aangesien die teikengebruiker daarin instruksies vind oor hoe om die woordeboek effektief te gebruik. Insigte uit die tekswetenskap kan benut word om gebruikersvriendelike metatekste te skep, wat op hulle beurt die woordeboeke wat hulle toelig gebruikersvriendeliker sal maak. Volgens Steehouder et al. (1999: 37) is die doel van instruktiewe kommunikasie om die ontvanger in staat te stel om bepaalde take uit te voer in die geval van 'n woordeboek: om die aangebode inligting te ontsluit. Verder word die volgende eise aan instruktiewe tekste gestel (Steehouder et al. 1999: 37-38):

(a) Die teks moet help om die taak effektief uit te voer, d.w.s. met so min as moontlik moeite.

(b) Die teks moet insig gee in die taak. Die leser moet nie slegs in staat wees om die taak uit te voer nie, maar ook om te verstaan waarmee hy/sy besig is.

(c) Soms is dit belangrik dat die taak aangeleer word. Dan moet die inligting leerbaar wees. Die woordeboekgebruiker wil byvoorbeeld nie elke 
keer wanneer hy/sy ' $n$ bepaalde woordeboek raadpleeg, eers weer in die metateks nalees hoe om die woordeboek te gebruik nie.

(d) Die leser van 'n instruktiewe teks moet ook gemotiveer word om die taak uit te voer.

Om aan hierdie eise te voldoen, behoort ' $n$ instruktiewe teks (soos die metateks in 'n woordeboek) volledig te wees: dit moet die gepaste hoeveelheid detail bevat, die stappe moet in die korrekte volgorde aangebied word en die taalgebruik moet so duidelik wees dat die leser verstaan wat hom/haar te doen staan (Steehouder et al. 1999: 38).

Dit is duidelik dat bogenoemde vereistes ook geld vir die stylgids wat as instruktiewe teks aan die leksikograaf gerig is.

\subsection{Die konteksparameter}

Die konteksparameter omvat daardie versameling veranderlikes wat normaalweg buite die beheer van die leksikograaf en die gebruiker in hulle onderskeie kapasiteite as sodanig val, maar waarbínne én die saamstel én die gebruik van die woordeboek plaasvind. Hoewel die leksikograaf en die gebruiker gewoonlik min aan die waardes van hierdie veranderlikes kan doen, moet dié veranderlikes so ver moontlik in die beplanning van 'n gebruikersvriendelike woordeboek verreken word. Hieronder volg enkele veranderlikes se waardes soos dit in die literatuur voorkom:

(a) Die vertalende woordeboek is in baie huise in 'n multitalige samelewing (soos in Suider-Afrika) die enigste bron van semantiese inligting in beide die moedertaal en die vreemde taal (Gouws 1996: 16).

(b) Daar is ' $\mathrm{n}$ gebrek aan woordeboekonderrig in skole in Suid-Afrika (Fouché-Van der Merwe 1999: 144).

(c) Die ouderdomme waarop kinders skool toe gaan, sowel as die standaarde van onderrig, wissel van instelling tot instelling (Fouché-Van der Merwe 1999: 145).

(d) Suid-Afrika is 'n multitalige samelewing (Gouws 1996: 18).

(e) Woordeboeke is nie geredelik op skool beskikbaar nie (Carstens 1995: 107).

(f) Onderwysers se benadering tot, kennis van en houding jeens woordeboeke is nie altyd na wense nie (Carstens 1995: 109).

(g) Woordeboeke word binne die konteks van 'n (nasionale) taalbeleid saamgestel (Bergenholtz en Gouws 2006: 14). 
Die beskrywing van die konteksparameter suggereer dat die verhouding tussen dié parameter en veral die woordeboekparameter 'n eensydige een is, m.a.w. die waardes van die veranderlikes binne die konteksparameter bepaal die waardes van die veranderlikes binne die woordeboekparameter, en nie andersom nie. Hoewel dit in baie gevalle inderdaad die geldende verhouding is, bestaan daar wel instansies waar die veranderlikes binne die woordeboekparameter ' $n$ beduidende invloed op die waardes van die veranderlikes binne die konteksparameter uitgeoefen het. 'n Sprekende voorbeeld van so 'n instansie is die verskyning van An American Dictionary of the English Language (Webster 1828), wat 'n beduidende en blywende invloed op die spelling van Amerikaanse Engels gehad het (vgl. Gouws 1989: 19; Landau 2001: 69-74). So ver as wat woordeboeke as normeerders van taal beskou en gebruik word, kan die waardes van die veranderlikes binne die konteksparameters wel deur die leksikograaf en woordeboekgebruiker in hulle onderskeie kapasiteite as sodanig beïnvloed word. Vergelyk in hierdie verband byvoorbeeld Bergenholtz en Gouws (2006) vir 'n bespreking oor die invloed van taalbeleid op die leksikografie. 'n Verdere voorbeeld wat die invloed van die konteksparameter op die gebruikersvriendelikheid van 'n bestaande woordeboek het, kan in terme van die ortografie van Engels in Namibië voorgehou word: In Namibië word die Britse ortografie van Engels ingevolge ' $n$ kabinetsbesluit toegepas. Daar is egter ook Engelse woordeboeke wat deur Amerikaanse uitgewers versprei word, in die Namibiese boekhandel beskikbaar. Hierdie woordeboeke gee uiteraard leiding oor die Amerikaanse ortografie van Engels, wat in bepaalde opsigte beduidend van die Britse ortografie afwyk. Binne die Namibiese konteks kan 'n woordeboek wat Amerikaanse Engels behandel, derhalwe nie in terme van hierdie parameter as gebruikersvriendelik beskou word nie.

\subsection{Die terugvoerparameter}

Tradisioneel figureer terugvoer nie in besprekings oor woordeboeke nie, hoofsaaklik omdat terugvoer deur die gebruiker nie onmiddellik kan plaasvind nie en omdat geen terugvoer enige onmiddellike effek op die woordeboek sal uitoefen nie, aangesien kritiek eers by 'n volgende uitgawe verreken kan word. Terugvoer is wel waardevol en kan bydra tot die verhoging in gebruikersvriendelikheid van 'n woordeboek. Terugvoer geskied gewoonlik in die vorm van resensies wat in die pers en in vaktydskrifte verskyn, en in die vorm van studies, referate en wetenskaplike artikels wat tydens leksikografiekongresse en in vaktydskrifte die resultate van woordeboeknavorsing en -kritiek weergee.

Die terugvoerparameter het nie slegs 'n invloed op die leksikograaf(parameter) nie, maar kan ook invloed op die gebruikersparameter, die gebruikersverwysingsraamwerkparameter én die konteksparameter uitoefen. Woordeboekresensies wat in die openbare pers verskyn, word immers nie slegs deur leksikograwe gelees nie (trouens, leksikograwe maak slegs 'n mikroskopiese 
fraksie van byvoorbeeld koerantlesers uit), maar kan ook op sekondêre vlak ' $n$ leksikografies-didaktiese funksie en selfs 'n voorligtingsfunksie in die breër gemeenskap vervul. 'n Leksikografies-didaktiese funksie word vervul indien die (koerant)leser iets oor die samestelling en nut van die woordeboek wat geresenseer word (en by implikasie van ander woordeboeke ook), leer; ' $n$ voorligtingsfunksie word vervul indien die breër gemeenskap (weer) deur die media bewus gemaak word van 'n bepaalde woordeboek en van woordeboeke oor die algemeen. In die vestiging van 'n woordeboekkultuur sal die verskyning van woordeboekresensies in die openbare pers 'n belangrike rol vervul.

In 'n relatief onlangse ontwikkeling in die metaleksikografie het De Schrijver en Prinsloo (2000) 'n model voorgestel waarvolgens die leksikograaf terugvoer van die teikengebruikers kan ontvang terwyl hy/sy nog met die saamstel van die woordeboek besig is. Hierdie tegniek noem De Schrijver en Prinsloo "gelyktydige terugvoering", en hoewel hier nie verder daarop ingegaan word nie, hou dié tegniek groot potensiaal vir die saamstel van gebruikersvriendelike woordeboeke in.

Die belang van die terugvoerparameter word daardeur onderstreep dat woordeboekkritiek een van die navorsingsgebiede in die metaleksikografie verteenwoordig.

\subsection{Samevattend}

Die toepassing van die aangepaste kommunikasiemodel op leksikografiese kommunikasie stel 'n nuttige teoretiese raamwerk daar waarbinne die gebuikersgedrewe leksikografie die veranderlikes wat dit bepaal, volledig kan verreken.

Soos reeds geblyk het, is dit belangrik om daarop te let dat die parameters binne die model nie in isolasie of onafhanklik van mekaar funksioneer nie, maar dat elke parameter in ' $n$ interafhanklike verhouding tot die ander parameters staan.

Die model wat steeds ontwikkel word, sal voorlopig die model van leksikografiese parameters vir gebruikersvriendelike woordeboeke heet. As model wat wil bydra tot die produksie van gebruikersvriendelike woordeboeke, moet dit binne die leksikografiese proses optree; in hierdie opsig vertoon dit 'n sterk verband met die woordeboekkonseptualiseringsplan binne die woordeboekplan, hoewel dit ook op die organisasieplan betrekking kan hê. Die optrede van die model van leksikografiese parameters vir gebruikersvriendelike woordeboeke kan gevolglik, soos in figuur 4 hieronder uitgebeeld, binne die leksikografiese proses geplaas word.

Soos figuur 4 toon, vind die skakeling tussen die model van leksikografiese parameters vir gebruikersvriendelike woordeboeke en veral die woordeboekkonseptualiseringsplan primêr deur die woordeboekparameter van die model plaas. 


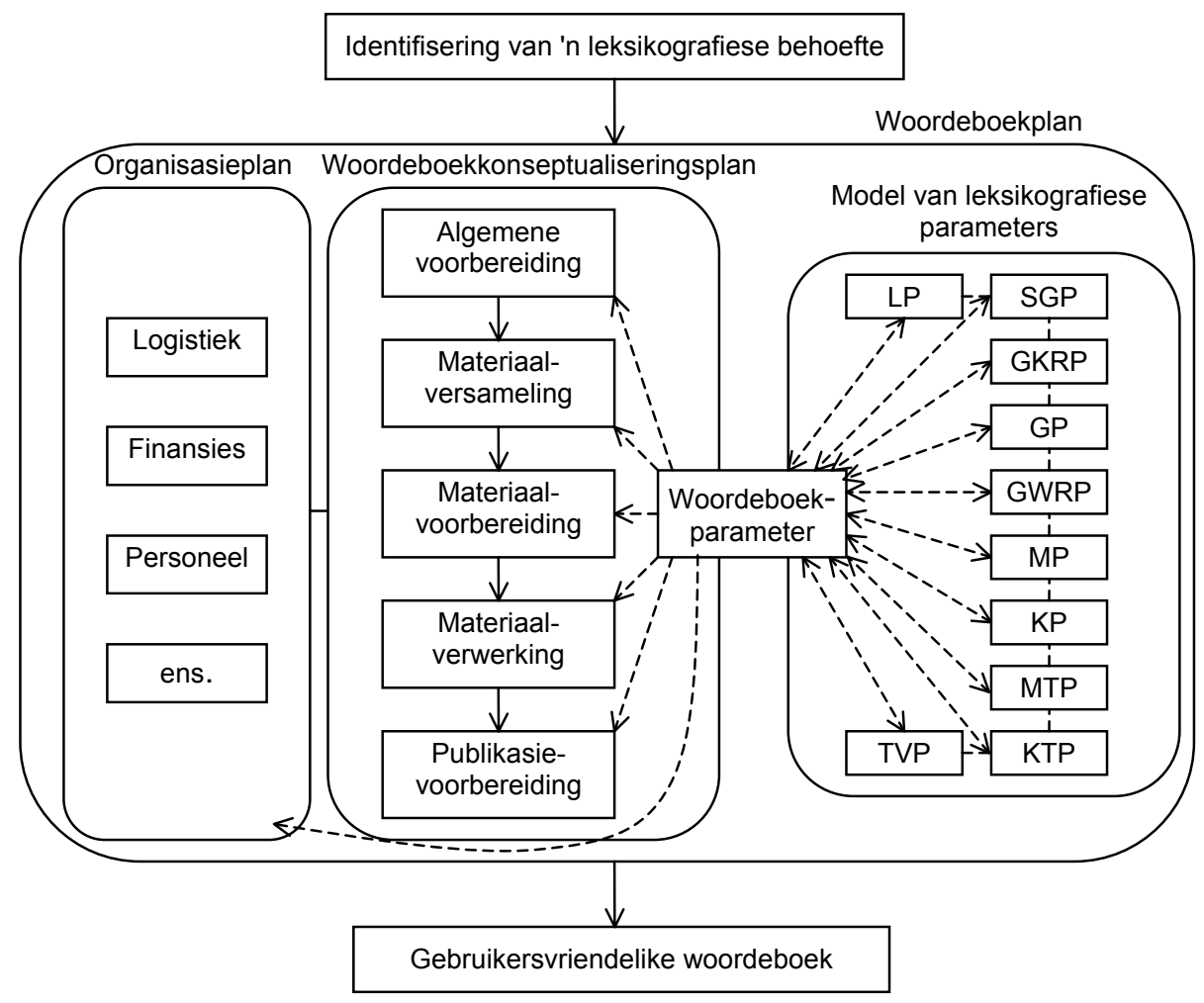

Figuur 4: Die funksionering van die model van leksikografiese parameters vir gebruikersvriendelike woordeboeke in die leksikografiese proses

Notasiekonvensie: " $\downarrow$ " rigting van die leksikografiese proses; " $x<---y "$ " y beïnvloed $x ; " x---y " x$ funksioneer in samehang met $y$. Afkortings: LP = leksikograafparameter; $\mathrm{SGP}=$ stylgidsparameter; $\mathrm{GKRP}=$ gebruikersparameter; $\mathrm{GP}=$ gebruiksparameter; GWRP = gebruikersverwysingsraamwerkparameter; MP = mediumparameter; KP = kanaalparameter; $\mathrm{MTP}=$ metateksparameter; $\mathrm{KTP}=$ konteksparameter; TVP = terugvoerparameter.

\section{Perspektief: 'n Definisie vir die werklike doel van 'n gebruikersvrien- delike woordeboek}

$\mathrm{Na}$ aanleiding van die model van leksikografiese parameters vir gebruikersvriendelike woordeboeke kan die formulering van 'n definisie vir die werklike doel van 'n gebruikersvriendelike woordeboek aangepak word.

Tarp (2000: 193) haal Wiegand se algemene formulering van die ware doel van 'n woordeboek soos volg aan: 
The genuine purpose of a lexicographic reference work is, according to Wiegand, "that it can be used to obtain information from its lexicographic data about the respective subject of the reference work (daß sie benutzt werden können, um aus ihren lexikographischen Daten Informationen über den jeweiligen Gegenstand der Nachschlagenwerk zu gewinnen)".

Tarp (2000: 193) kritiseer hierdie definisie omdat dit na sy mening te algemeen is (hoewel hy toegee dat sodanige definisie in sy aard algemeen sal en behoort te wees). $\mathrm{Na}$ aanleiding van sy bespreking oor leksikografie en terminologie, die gebruikers en hulle eienskappe, gebruiksituasies, gebruikersbehoeftes en leksikografiese funksies, stel Tarp (2000: 198) 'n alternatiewe definsie voor:

The dictionary covers this or that area and is conceived to assist users with these or those characteristics in this or that situation in order to solve problems of this or that sort.

Hoewel Tarp se definisie nie veel aan eksaktheid wen nie, word die gebruikersparameter en die gebruiksparameter tereg ingereken.

Gouws (2001: 65) verskaf 'n vergelykbare definisie, maar voeg die rol van die teikengebruiker by:

[A dictionary's] genuine purpose is to transfer, by means of lexical data, information regarding the set of lexical items included as treatment units in order to ensure the linguistic empowerment of the intended target user.

Met die voordeel van die insig wat die model van leksikografiese parameters vir gebruikersvriendelike woordeboeke bied, kan vervolgens 'n generiese definisie vir die werklike doel van 'n gebruikersvriendelike woordeboek voorgestel word, wat ook elemente van die voorgaande definisies bevat:

Die werklike doel van 'n bepaalde tipe woordeboek is om binne 'n bepaalde konteks deur middel van 'n bepaalde medium via 'n bepaalde kanaal vanuit die woordeboekbasis, na aanleiding van die stylgids, wat in die metateks verantwoord is, in 'n bepaalde woordeboekteks (gewoonlik 'n woordeboekartikel) 'n bepaalde gebruikersvraag van die teikengebruiker, wat in 'n bepaalde gebruiksituasie verkeer en wat die woordeboek vanuit 'n bepaalde gebruikersverwysingsraamwerk benader, te beantwoord ten einde die talige bemagtiging van die teikengebruiker te verseker.

\section{Bronnelys}

\section{Woordeboeke}

Elektroniese Verklarende Handwoordeboek van die Afrikaanse Taal 2.00. 2000. Midrand: Perskor. (CD$\mathrm{ROM})$

Pharos Woordeboeke / Dictionaries: 5 in 1. 2000. Kaapstad: Pharos. (CD-ROM) 
The Oxford Talking Dictionary. 1998. Oxford: Oxford University Press. (CD-ROM)

Webster, N. 1828. An American Dictionary of the English Language. New York: S. Converse.

\section{Ander bronne}

Alberts, M. 1992. Behoeftebepaling in die leksikografie. Lexikos 2: 1-27.

Bergenholtz, H en R.H. Gouws. 2006. How to Do Language Policy with Dictionaries. Lexikos 16: 13-45.

Bergenholtz, H. en J. Mugdan (Reds.). 1985. Lexikographie und Grammatik. Akten des Essener Kolloquiums zur Grammatik im Wörterbuch 28.-30.6.1984. Lexicographica. Series Maior 3. Tübingen: Max Niemeyer.

Botha, W.F. en E. Botha. 1998. Lexicographic Training at the Bureau of the Woordeboek van die Afrikaanse Taal. Lexikos 8: 276-281.

Carstens, A. 1995. Language Teaching and Dictionary Use: An Overview. Lexikos 5: 105-116.

De Schryver, G.-M. en D.J. Prinsloo. 2000. The Concept of "Simultaneous Feedback": Towards a New Methodology for Compiling Dictionaries. Lexikos 10: 1-31.

Emejulu, J.D. (Red.). 2001. Éléments de lexicographie gabonaise. Tome I. New York: Jimacs-Hillman.

Fouché-Van der Merwe, M. 1999. Gebruikersperspektief in die Afrikaanse leksikografie. Ongepubliseerde D.Litt.-proefskrif. Stellenbosch: Universiteit van Stellenbosch.

Frost, R., H. Vos en M. Dreyer. 1993. Kommunikasie dinamiek. Johannesburg: Lexicon.

Gouws, R.H. 1989. Leksikografie. Pretoria/Kaapstad: Academica.

Gouws, R.H. 1990. Information Categories in Dictionaries, with Special Reference to Southern Africa. Hartmann, R.R.K. (Red.). 1990: 52-65.

Gouws, R.H. 1996. Leksikografiese behoeftevervulling. Lexikos 6: 171-183.

Gouws, R.H. 1996a. Bilingual Dictionaries and Communicative Equivalence for a Multilingual Society. Lexikos 6: 14-31.

Gouws, R.H. 1999. Die maatskaplike gerigtheid van die metaleksikografie in 'n meertalige samelewing. Intreerede. Stellenbosch: Universiteit van Stellenbosch Drukkery.

Gouws, R.H. 2001. Lexicographic Training: Approaches and Topics. Emejulu, J.D. (Red.). 2001: 5894.

Gouws, R.H. en D.J. Prinsloo. 2005. Principles and Practice of South African Lexicography. Stellenbosch: SUN PReSS.

Guffey, M.E. 2001. Essentials of Business Communication. Cincinnati: South-Western College Publishing.

Hartmann, R.R.K. (Red.). 1984. LEXeter '83 Proceedings. Papers from the International Conference on Lexicography at Exeter, 9-12 September 1983. Lexicographica. Series Maior 1. Tübingen: Max Niemeyer.

Hartmann, R.R.K. 1989. Sociology of the Dictionary User: Hypotheses and Empirical Studies. Hausmann, F.J. et al. (Reds.). 1989-1991: 102-111.

Hartmann, R.R.K. (Red.). 1990. Lexicography in Africa. Progress Reports from the Dictionary Research Centre Workshop at Exeter, 24-25 March 1989. Exeter Linguistic Studies 15. Exeter: University of Exeter Press.

Hausmann, F.J., O. Reichmann, H.E. Wiegand en L. Zgusta. (Reds.). 1989-1991. Wörterbücher. Ein internationales Handbuch zur Lexikographie/Dictionaries. An International Encyclopedia of Lexicography/Dictionnaires. Encyclopédie internationale de lexicographie. Handbücher zur Sprach- und Kommunikationswissenschaft 5.1-5.3. Berlyn/New York: Walter de Gruyter. 
Janssen, D. (Red.). 1996³. Zakelijke communicatie 1. Groningen: Wolters-Noordhoff.

Kirkpatrick, B. 1989. User's Guides in Dictionaries. Hausmann, F.J. et al. (Reds.). 1989-1991: 754761.

Kromann, H.-P., T. Riiber en P. Rosbach. 1991. Principles of Bilingual Lexicography. Hausmann, F.J. et al. (Reds.). 1989-1991: 2711-2728.

Kühn, P. 1989. Typologie der Wörterbücher nach Benutzungsmöglichkeiten. Hausmann, F.J. et al. (Reds.). 1989-1991: 111-127.

Landau, S.I. 20012. Dictionaries. The Art and Craft of Lexicography. Cambridge: Cambridge University Press.

Lombard, F.J. 1994. Lexicographer, Linguist and Dictionary User: An Uneasy Triangle? Lexikos 4: 204-214.

Louw, P. 2000. Guide Structures in CD-ROM Dictionaries, with Specific Reference to the EWED and the ELHAT. Lexikos 10: 291-305.

Louw, P. 2001. Resensie van Pharos Woordeboeke/Dictionaries 5 in 1: 5 ten volle geïntegreerde woordeboeke/Fully Integrated Dictionaries op CD-ROM. Lexikos 11: 324-327.

Louw, P.A. 1997. Kriteria vir 'n standaard vertalende woordeboek. Ongepubliseerde M.A.-skripsie. Stellenbosch: Universiteit van Stellenbosch.

Martin, W. 1994. Lexicologie als universitaire vakopleiding. Lexikos 4: 215-229.

Prinsloo, D.J. en R.H. Gouws. 2000. The Use of Examples in Polyfunctional Dictionaries. Lexikos 10: 138-156.

Read, A.W. 1973. Approaches to Lexicography and Semantics. Sebeok, T.A. (Red.). 1973: 145-205.

Sebeok, T.A. (Red.). 1973. Current Trends in Linguistics 10. Den Haag/Parys: Mouton.

Smit, M. 1996. Wiegand's Metalexicography as a Framework for a Multilingual, Multicultural, Explanatory Music Education Dictionary for South Africa. Ongepubliseerde D.Litt.-proefskrif. Stellenbosch: Universiteit van Stellenbosch.

Steehouder, M., C. Jansen, K. Maat, J. van der Staak, D. de Vet, M. Witteveen, E. Woudstra. 19994. Leren communiceren. Groningen: Walters-Noordhoff.

Steinberg, S. 1994. Introduction to Communication. Kaapstad: Juta.

Svensén, B. 1993. Practical Lexicography. Principles and Methods of Dictionary-Making. Oxford: Oxford University Press.

Swanepoel, P. 2001. Dictionary Quality and Dictionary Design: A Methodology for Improving the Functional Quality of Dictionaries. Lexikos 11: 160-190.

Tarp, S. 2000. Theoretical Challenges to Practical Specialised Lexicography. Lexikos 10: 189-208.

Van Cuilenburg, J.J., O. Scholten en G.W. Noomen. 1992. Communicatiewetenschap. Bussum: Coutinho.

Van der Molen, H.T., F. Kluytmans en M. Kramer. 1995. Gespreksvoering: Vaardigheden en modellen. Groningen: Wolters-Noordhoff.

Wiegand, H.E. 1984. On the Structure and Contents of a General Theory of Lexicography. Hartmann, R.R.K. (Red.). 1984: 13-30.

Wiegand, H.E. 1985. Fragen zur Grammatik in Wörterbuchbenutzungsprotokollen. Ein Beitrag zur empirischen Erforschung der Benutzung einsprachiger Wörterbücher. Bergenholtz, H. en J. Mugdan (Reds.). 1985: 20-98.

Wiegand, H.E. 1996. A Theory of Lexicographic Texts: An Overview. South African Journal of Linguistics 14(4): 134-149. 